\title{
Saffron Oil
}

National Cancer Institute

\section{Source}

National Cancer Institute. Saffron Oil. NCI Thesaurus. Code C107361.

The oil extracted from the stigmas of the Crocus sativus flower. Saffron oil is used for external application in uterine sores. 